\title{
Peptic (contact ulcer) granuloma of the larynx
}

\author{
T L MIKO \\ From the Department of Pathology, University Medical School of Debrecen, Debrecen, Hungary
}

SUMMARY Review of published work and analysis of clinical data and pathology of four biopsy specimens from two patients with laryngeal contact granuloma showed that its peptic origin was derived from a gastro-oesophago-laryngeal reflux. It is proposed that the term "peptic granuloma" should be given to this phenomenon. This term is given further support on account of the spectacular recovery of the laryngeal lesion following antacid and antireflux treatment, rather than the traditional method of using vocal rest and speech therapy, assumed to be the best way of treating a result of mechanical irritation, the previously accepted cause of laryngeal contact granuloma.

Contact ulcer granuloma of the larynx is common in published reports on laryngology, ${ }^{1-18}$ but reports on its pathology are scarce. ${ }^{19-20}$ Several suggestions for its aetiology have been put forward. Mechanical stress has been the generally accepted cause, but treatment for this has given poor results and the lesion is prone to recur after surgery. More recent reports ${ }^{12} 12^{20-22}$ have shown that patients with contact ulcer may have oesophageal dysfunction as well. Analysis of the available data on this condition shows a role for regurgitated gastric juice.

This study aims to describe the pathology of the socalled contact ulcer granuloma of the larynx, a condition of which pathologists should be aware. Successful interpretation of the laryngeal specimen may draw the clinician's attention to an underlying, frequently hidden gastro-oesophageal disorder.

\section{Case reports}

CASE 1

A 48 year old manager complained of hoarseness which had been getting progressively worse for several months. He had never been intubated. A mass the size of a french bean was removed in fragments from his right vocal process of the arytenoid cartilage. It was thought to be an ulcerated polyp of the vascular type. In spite of voice rest it recurred and was again excised four months later. Identical morphologcal detail and location of the lesions prompted the diagnosis of contact ulcer granuloma (fig 1). Questioned about his digestive history, the patient stated that he had symptoms of reflux oesophagitis. A month after the second operation a barium meal picture showed a chronic duodenal ulcer and hyperacidity, but no

Accepted for publication 31 March 1989 oesophageal reflux was shown on $x$-ray picture. The clinical features were, however, unequivocal, so that a repeated $x$-ray examination was considered to be unnecessary. The treatment of hyperacidity and reflux oesophagitis resulted in complete recovery of the laryngeal lesion in two months. After another five months the patient was lost to follow up. It was later learnt that after having neglected to take the prescribed treatment his symptoms recurred. In a county hospital a third "polypectomy" was carried out one year after the second surgery. Histological examination showed that the contact granuloma was fibrous with a thickened epithelium (fig 2). The anti-reflux regimen was restarted; he has been free of symptoms for five years.

\section{CASE 2}

A 54 year old motor mechanic who had never been intubated presented with increasing hoarseness over three months. A spherical mass of 3-4 mm in diameter removed from the left vocal process was histologically confirmed as contact granuloma (fig 3). He was noted to be softly spoken. For one year he had experienced the appearance of some acidic material in his throat after consuming spicy food. One week after the biopsy an $x$-ray picture showed that he had gastrooesophageal reflux. As a result of conservative antireflux measures his symptoms resolved and the laryngeal biopsy site disappeared in two weeks. His larynx has been normal for three years.

\section{Aetiology}

Jackson was the first to emphasise that the aetiology of this disease, which occurs mainly in middle aged men, is the mechanical impact of overforceful adduction of 


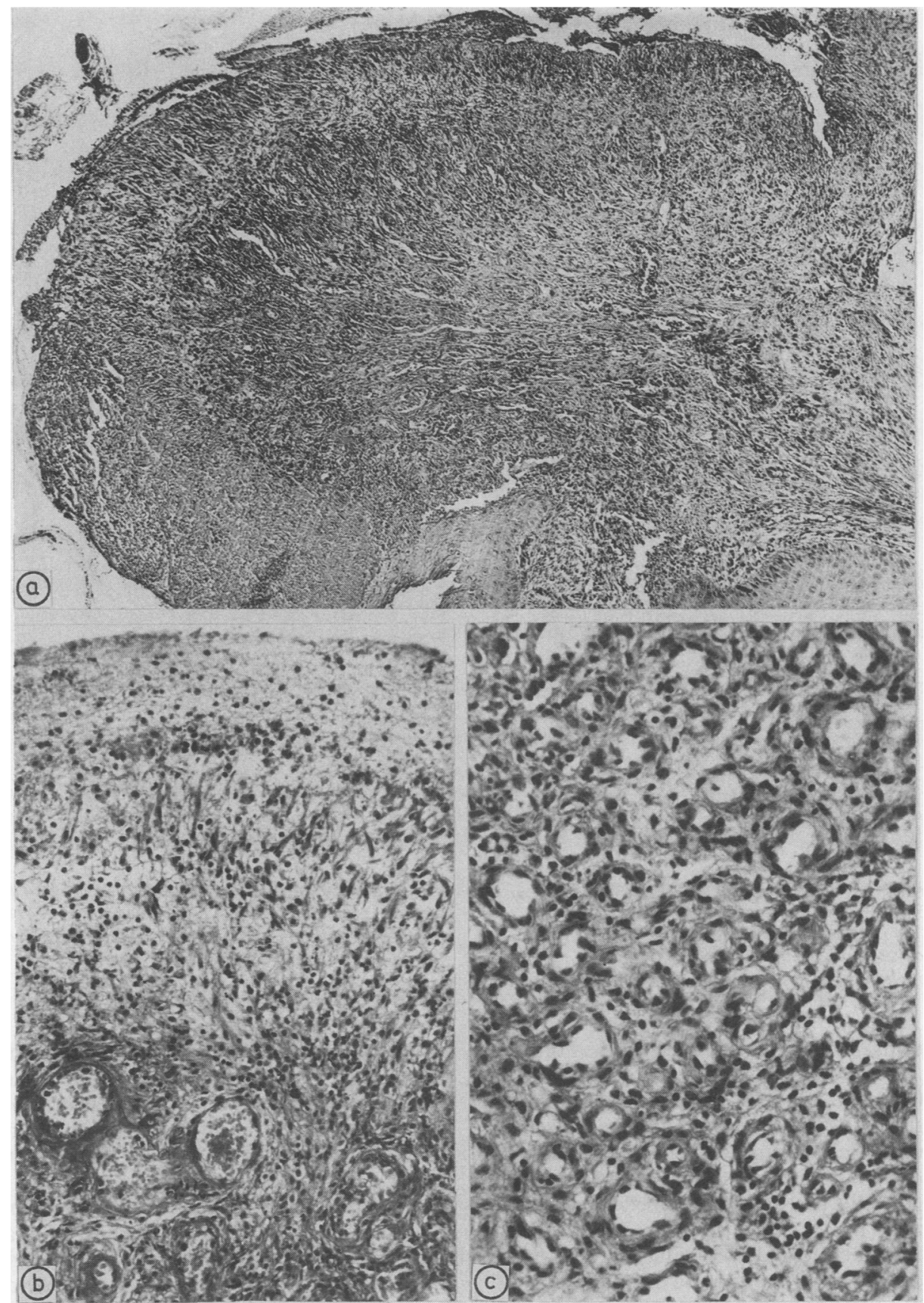

Fig 1 Basic features of laryngeal peptic gramuloma (case 1, second biopsy specimen). (a) Low power view shows ulcerated non-specific gramulation tissue bulging over the original surface. The preserved squamous epithelium of the vocal cord is discernible at the bottom. (Haematoxylin and eosin.) (b) A characteristic feature is the central core of capillaries covered by a layer of fibroblasts and a necrotic fibrinous mass. Inflammatory cells are scattered evenly throughout the lesion.

(Haematoxylin and eosin.) (c) The tangentially cut capillary area shows lumina of similar calibre covered by plump endothelial cells resembling capillary haemangioma. (Haematoxylin and van Gieson.) 


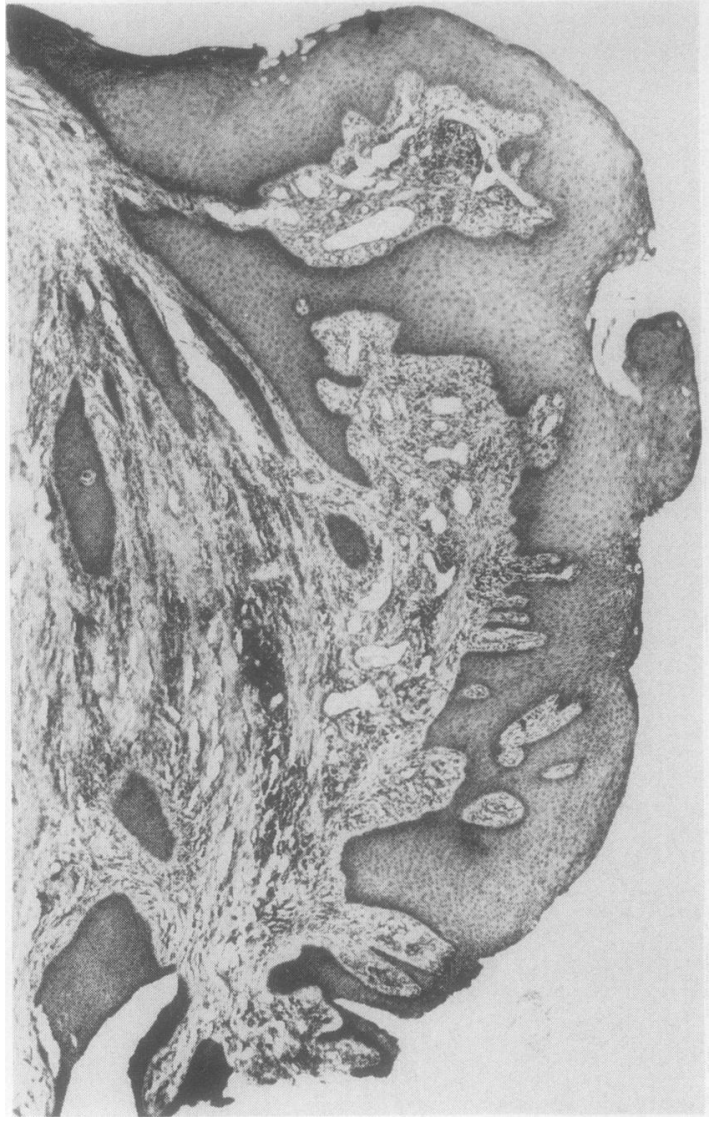

Fig 2 Late stage of peptic gramuloma showing fibrotic granulation tissue with wide capillaries and focal chronic inflammation (case 1, third biopsy specimen). The thick epithelial covering is complete and shows pseudoepitheliomatous hyperplasia. (Haematoxylin and eosin.)

the arytenoids during phonation. ${ }^{1} \mathrm{He}$ coined the term "contact ulcer". After a while, granulation tissue emerges from the edges of the ulcer, so New and Devine termed it "contact ulcer granuloma". 6 Damage to the mucoperichondrium, which covers the vocal process, by phonation at low frequencies, by coughing and clearing of the throat was described by von Leden and Moore, ${ }^{10}$ but no direct association was made between these factors and the contact ulcer. Contact ulcer is also rare in actors who use their voices a lot." Vocal therapy and repeated excisions have proved to be of little benefit as the lesion either stubbornly persists or recurs. ${ }^{11} 16$

The three patients reported by Cherry and Margulies $^{12}$ who were refractory to voice rest, vocal rehabilitation, antibiotics and steroids, had gastrooesophageal reflux and peptic oesophagitis. The sym-

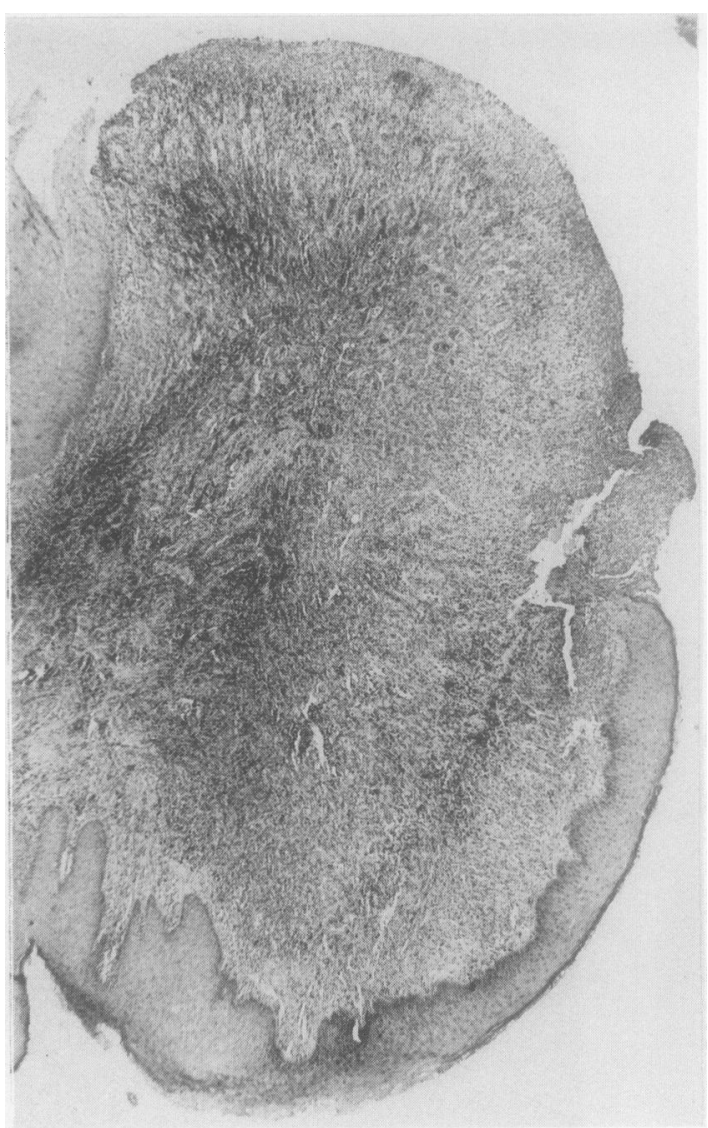

Fig 3 The peptic granuloma is partially covered with newly formed epithelium (case 2). Note the typical layering at the top and the total absence of any lobular arrangement. (Haematoxylin and eosin.)

ptoms of peptic oesophagitis were so mild that the patients did not complain. Treatment of the gastrooesophageal disorder alone resulted in a permanent recovery of the laryngeal changes within a maximum of six months. The authors suggested that the acidic reflux was an additional pathogenic factor and that this material caused the breakdown of the vocal chord mucosa, stimulating the production of granulation tissue. The possibility of regurgitated material reaching the respiratory system has also been described, ${ }^{23} 24$ and in $16 \%$ of such cases respiratory symptoms are the only sign of gastro-oesophageal reflux. ${ }^{23}$

In 1978 Goldberg et al described a recurring laryngeal granuloma in a patient with gastro-oesophageal regurgitation, ${ }^{21}$ unaware of the reflux theory of the contact granuloma.

Cinematographic and cineradiographic studies led 
Ward and his colleagues in 1980 to state that the contact ulcers and granulomas were the result of habitual throat clearing, secondary to either a local irritation of the larynx from nasal secretions or, more often, by regurgitated gastric juice at night as a result of hiatus hernia. ${ }^{14}$ Öhman et al verified 32 cases of oesophageal dysfunction and 11 active gastroduodenal ulcers in 43 patients with contact ulcer using complex methods. ${ }^{16}$ Clinical signs of oesophageal dysfunction were present in less than one third of the cases.

Observations on the pathogenetic role of refluxed gastric juice in chronic posterior laryngitis have also been made. ${ }^{25} 26$ In 1982 Ward and Berci considered chronic non-specific pharyngitis, laryngitis, contact ulcers and granulomas to be members of the same spectrum. ${ }^{22}$ There have been attempts to differentiate "hyperacidic" and "hyperfunctional" granulomata ${ }^{1517}$; as well as vocal ulcer and vocal chord granuloma, ${ }^{18}$ but with little conclusive evidence to date.

\section{Morphology}

The lesion usually appears as a unilateral cup-like depression on the vocal process mucosa ${ }^{120}$ and may also occur on the posterior commissure; the term "posterior commissure ulcer" is therefore also used. ${ }^{19}$ Histological examination shows that the ulcer is covered with tissue debris, inflammatory exudate, and granulation tissue and rarely reaches the underlying cartilage. ${ }^{6}$ Shortly afterwards, granulation tissue grows from the edges and exuberant non-specific granulation tissue is superimposed, which is friable on removal. Pathologists usually see this form in biopsy specimen (figs 1 and 3 ). The lesion is divided into three parts. The basal portion, the bulkiest, is composed of newly formed capillaries. The deepest area usually contains collagen fibres, the amount of which decreases more superficially where the capillary lumina are narrower and are covered by plump endothelium. The interstitium may be pigmented with haemosiderin. The capillaries disappear rather abruptly and the middle layer almost exclusively comprises fibroblasts arranged radially. The thickness of the fibrinous exudate covering the surface is variable and contains tissue debris. A moderate amount of neutrophils are present in all portions of the lesion and a scanty infiltration of lymphocytes and eosinophils may also be evident (figs $1 \mathrm{~b}$ and $\mathrm{c}$ ). The tip of the vocal process of the arytenoid may be necrotic and loose cartilage may appear in the granuloma as well. Sometimes pseudoepitheliomatous hyperplasia surrounds the lesion. Long standing granulomas (fig 2) may be fibrous with a few blood vessels, the whole covered by epithelium. ${ }^{6711}$
In contrast, the vocal chord polyp may affect the entire length of the membranous chord in accordance with the length of Reinke's space, but is usually situated more anteriorly. Its structure depends on the fate of the initial exudate and the connective tissue reaction. Ingrowths of blood vessels may produce a predominantly vascular tissue which may be mistaken for angioma ${ }^{20}$ or contact granuloma. It may be extensively ulcerated and may contain haemosiderin, like contact granuloma. The stromal oedema and the numerous, randomly distributed cavernous blood vessels, typical of polyps, distinguish it from the contact granuloma. Sinusoid-like lumina are rarely seen in the latter, but when this does happen they are found in the centre of the deepest region.

True laryngeal angiomata are excessively rare. Most of the lesions that have been so diagnosed were probably polyps of the vascular type. ${ }^{20}$ Infraglottic and supraglottic aggressive haemangiomas occasionally found in children and adolescent $\mathrm{s}^{20}$ present no diferential diagnostic problem in this context. According to Mills $e t$ al, ${ }^{27}$ the diagnostic criterion for pyogenic granuloma is a distinctly lobular arrangement; thus the term "lobular capillary hemangioma" has been suggested. The authors found no such lesion in 68 vascular changes studied in tissue from the larynx and trachea.

Intubation granuloma heals spontaneously in all but $1-2 \%$ of cases. It is usually found on the vocal process of the arytenoids. The histological detail is similar to that of contact granuloma, ${ }^{20}$ and after a while it may also be covered by epithelium. ${ }^{628}$ Assuming a similar pathogenesis for all these lesions, Jackson lumped them together. ${ }^{7}$ Why contact granuloma persists, however, is unknown: a subclinical gastrooesophageal reflux might be a contributory factor.

\section{Discussion}

A similar aetiology has been proposed both for contact granuloma and laryngeal polyp $p^{167101114}$ despite the quite different location, pattern of reaction, and contrasting results of speech therapy. Vocal stress cannot be accepted as the aetiology of contact granuloma. It is worth noting that several authors have noticed the disease typically occurring in tense, ambitious people-that is, prone to ulcers, ${ }^{611}$ and Jackson reported that several of his patients had complained of waking up at night choking on and coughing up secretions in the larynx.'

After the association between contact granuloma and the gastro-oesophageal reflux had been recognised $^{12}$ the lesion was attributed to throat clearing ${ }^{14}$ and an enhanced coughing reflex evoked by regurgitation. ${ }^{16}$ But these authors neglected to take into consideration the numerous patients without reflux 
but long standing coughing and throat clearing who did not have laryngeal granuloma. It now seems likely that coughing and throat clearing are not causal but secondary factors because of the vicinity of the granuloma to the chords. Direct contact of the gastric juice on the laryngeal mucosa is more likely, but of a rather more severe kind than Cherry and Margulies indicated. ${ }^{12}$ The regurgitated acid and bile passing into the larynx principally bathes the dorsal portion of the vocal chords. In this region the mucoperichondrium covering the vocal processes is the most vulnerable and this may influence localisation. This feature, however, is generally considered to be secondary because the laryngeal disorder is curable by treating only the reflux,,$^{121421}$ in accordance with the findings in our cases. The mechanical origin is all the more unlikely because of the occurrence of the lesion on the posterior commissure, ${ }^{17} 19$ where mechanical impact could not be an important factor. Furthermore, the primary role of gastric juice has been documented by experimentally producing an identical lesion in dogs. ${ }^{13}$

I would therefore suggest that the term "peptic granuloma" is the most appropriate because antacid and anti-reflux treatment provides a reliable cure.

I am indebted to Professor L Michaels for his constructive comments. Dr G Sotonyi and Dr G Krajczar kindly provided the third biopsy specimen of case 1 and that of 2 .

\section{References}

1 Jackson C. Contact ulcer of the larynx. Ann Otol Rhinol Laryngol 1928;37:227-30.

2 Jackson CL. Etiology and treatment of contact ulcer of the larynx. Laryngoscope 1933;43:718-21.

3 Jackson C, Jackson CL. Contact ulcer of the larynx. Arch Otolaryngol 1935;22:1-15.

4 Woodruff GH. Contact ulcers of the larynx. JAMA 1936;106:1562-9.

5 Peacher G, Holinger P. Contact ulcer of the larynx; the role of reeducation. Arch Otolaryngol 1947;46:617-23.

6 New GB, Devine KD. Contact ulcer granuloma. Ann Otol Rhinol Laryngol 1949;58:548-58.

7 Jackson C. Contact ulcer granuloma and other laryngeal complications of endotracheal anesthesia. Anesthesiology 1953;14:425-36.
8 Baker DC Jr. Contact ulcer of the larynx. Laryngoscope 1954;64:73-8.

9 Holinger PH, Johnston KC. Contact ulcer of the larynx. JAMA 1960;172:511-5.

10 von Leden H, Moore P. Contact ulcer of the larynx. Arch Otolaryngol 1960;72:746-52.

11 Brodnitz FS. Contact ulcer of the larynx. Arch Otolaryngol 1961;74:90-100.

12 Cherry J, Margulies SI. Contact ulcer of the larynx. Laryngoscope 1968;78:1937-40.

13 Delahunty JE, Cherry J. Experimentally produced vocal cord granulomas. Laryngoscope 1968;78:1941-7.

14 Ward PH, Zwitman D, Hanson D, Berci G. Contact ulcers and granulomas of the larynx: new insights into their etiology as a basis for more rational treatment. Otolaryngol Head Neck Surg 1980;88:262-9.

15 Bloch CS, Gould WJ, Hirano M. Effect of voice therapy on contact granuloma of the vocal fold. Ann Otol Rhinol Laryngol 1981;90:48-52.

16 Ohman L, Tibbling J, Olofsson J, Ericsson G. Esophageal dysfunction in patients with contact ulcer of the larynx. Ann Otol Rhinol Laryngol 1983;92:228-30.

17 Feder RJ, Michell MJ. Hyperfunctional, hyperacidic and intubation granulomas. Arch Otolaryngol 1984;110:582-4.

18 Benjamin B, Croxon G. Vocal cord granulomas. Ann Otol Rhinol Laryngol 1985;94:538-41.

19 Rosai J. Ackerman's surgical pathology. St Louis: CV Mosby, 1981.

20 Michaels L. Ear nose and throat histopathology. Heidelberg: Springer Verlag, 1987.

21 Goldberg M, Noyek AM, Pritzker KPH. Laryngeal granuloma secondary to gastro-esophageal reflux. J Otolaryngol 1978;7:196-202.

22 Ward PH, Berci G. Observations on the pathogenesis of chronic non-specific pharyngitis and laryngitis. Laryngoscope 1982;92:1377-82.

23 Urschel H, Paulson DL. Gastroesophageal reflux and hiatal hernias complicating therapy. J Thorac Cardiovasc Surg 1967;53:21-32.

24 Barish CF, Wu WC, Castell DO. Respiratory complications of gastroesophageal reflux. Arch Intern Med 1985;145:1882-8.

25 Delahunty JE. Acid laryngitis. J Laryngol Otol 1972;86:335-42.

$26 \mathrm{Kambič} \mathrm{V,} \mathrm{Radšel} \mathrm{Z.} \mathrm{Acid} \mathrm{posterior} \mathrm{laryngitis:} \mathrm{Aetiology,} \mathrm{his-}$ tology, diagnosis and treatment. J Laryngol Otol 1984;98: $1237-40$.

27 Mills SE, Cooper PH, Fechner RE. Lobular capillary hemangioma: the underlying lesion of pyogenic granuloma. Am J Surg Pathol 1980;4:471-9.

28 Snow JC, Harano M, Balogh K. Post-intubation granuloma of the larynx. Anesthesia and Analgesia 1966;45:425-9.

Requests for reprints to: Dr T L Miko, Armaver Hansen Research Institute, POB 1005, Addis Ababa, Ethiopia. 